\title{
DISTRIBUTION AND ORIGIN OF FACTOR V LEIDEN: REVISITED WITH NEW APPROACH AND SUPPOSITIONS
}

\author{
Mehrez M. Jadaon \\ Department of Medical Laboratory Sciences, Faculty of Allied Health Sciences, Kuwait \\ University, Kuwait
}

\author{
EDITORIAL PAPER \\ Phlebological Review 2016; 24, 2-3: 38-39 \\ DOl: https://doi.org/10.5114/pr.2016.65517 \\ Submitted: 15.11 .2016
Accepted: 6.12 .2016 \\ ADDRESS FOR CORRESPONDENCE \\ Mehrez M. Jadaon \\ Department of Medical Laboratory Sciences \\ Faculty of Allied Health Sciences \\ Kuwait University \\ P.O. Box 31470 \\ 90805 Sulaibekhat, Kuwait \\ e-mail: mehrez@hsc.edu.kw
}

In this edition of "Phlebological Review" there is an interesting review article discussing the distribution of Factor V Leiden (FVL) mutation and arguing the origin of this mutation [1]. To briefly remind the reader, FVL is a missense point mutation (G1691A) in the clotting factor $\mathrm{V}(\mathrm{FV})$ gene, leading to an amino acid change in the $\mathrm{FV}$ molecule (Arg506Gn). FV is an important cofactor for the clotting system that prevents blood loss in cases of injuries. It is usually inactivated by activated protein $\mathrm{C}$ (APC) at amino acid position 506 of the FV molecule, the position that is affected by FVL. Therefore, this mutation renders FV to resist inactivation (a condition termed as APC-resistance), and this causes increased tendency towards clotting, which may be clinically manifested as venous thromboembolic disorders (VTE) with serious health issues that may be fatal [2]. Since its identification in 1993/1994 [3, 4], APC-resistance due to FVL has been found to be in high percentage of healthy individuals and patients with VTE. However, this was true in populations of Caucasian origin, but the mutation was very rare or absent in non-Caucasians $[2,5]$.

The confined presence of FVL in Caucasians brought speculations that the mutation might have occurred as a single event in a Caucasian ancestor. This was explored by few researchers, including the writer of these lines, who found certain single nucleotide polymorphisms (SNP) to be in linkage disequilibrium with FVL, supporting the hypothesis of a single origin in a single ancestor [6-10]. Taking the research further steps forward, researchers combined the molecular results with the geographic distribution of FVL and the available anthropological data, trying to find where and when this single ancestor might have lived. Some researchers suggested that the ancestor had lived somewhere in Europe after the
Caucasoid-Mongoloid separation (around 32,000 years go), while others thought it should have happened in the East Mediterranean area or Turkey (the Near East) (about 10,000 years ago), and then moved to Europe with the migration of Neolithic farmers [2, 5].

In the article by Simka and Latacz [1], the authors propose a new interesting hypothesis on the origin of FVL. The authors present their opinion based on current available data, including molecular studies on current human samples and on archeological human remnants, geographic distribution of FVL in the Near East and Europe (including isolated ethnic groups), and anthropological and linguistics materials. The authors first discussed studies that conveyed that pre-Neolithic Europe should have been free from FVL until the movement of Neolithic farmers from the Near East to Europe, which happened about 9,500 years go. However, molecular studies presented evidences that the mutation had occurred about 21,000-32,000 years ago. This brings up the argument that: if FVL occurred first in the Near East (about 21,000-32,000 years ago), but did not move to Europe until around 10,000 ago; this means that the mutation should have stayed in the Near East for a very long period of time (more than 10,000 years) without being transmitted to neighboring areas (towards Europe or Asia). The authors thought this was very unlikely, and they presented their hypothesis that might explain, in their opinion, this gap in time. They proposed that FVL might have occurred in a hypothetical ancient kind of humans so-called Basal Eurasians. These were a group of population that came out of Africa, like the ones known to leave Africa around 100,000 years ago toward the Middle East and then to the rest of the world. What is different is that the Basal Eurasians settled probably 
somewhere in the Middle East or North Africa, and did not go along the mainstream of migration to Eurasia. Based on this, Simka and Latacz hypothesized that FVL might have occurred first in the Basal Eurasians more than 20,000 years ago, who lived isolated for thousands of years somewhere in North Africa, between mountains and deserts of Sahara and the Mediterranean Sea, and this caused genetic isolation in this population, including the FVL mutation. Then, they migrated to the Near East about 10,000 years ago because of, and again hypothesized by the authors, the dramatic climate change called Younger Dryas (approximately 12,000 years ago) that forced them to move to the Middle East. They supported their hypothesis by the results of studies on the genetic pools of modern humans (Europeans, Asians, Middle Eastern) in comparison with genetics of the Basal Eurasians and other pre-historic relatives of humans like the Neanderthals, who lived in Europe and Near East, but not Africa.

Still, these hypotheses have a long journey to go before being proven, especially that the Basal Eurasians themselves are hypothetical kind of ancestry that no longer exists in pure form, and that we are not even sure that they really existed, since we do not have any old or modern samples of them. More molecular and archeological studies are definitely needed before reaching final conclusions on the origin of FVL. Still, Simka and Latacz presented new thoughts that deserve to be read and observed.

\section{The authors declare no conflict of interest.}

\section{References}

1. Simka M., Latacz P. Factor V Leiden distribution - could it shed some light at prehistory of Europe and the Near East? Phlebol Rev 2016; 24: 40-45.

2. Jadaon M.M. Aetiology of Venous Thrombosis. In: Ertugrul Okuyan (ed.). Venous Thrombosis - Principles and Practice. InTech, Rijeka, Croatia 2011; pp. 3-42.

3. Dahlbäck B., Carlsson M., Svensson P.J. Familial thrombophilia due to a previously unrecognized mechanism characterized by poor anticoagulant response to activated protein C: Prediction of a cofactor to activated protein C. Proc Natl Acad Sci U S A 1993; 90: 1004-1008.

4. Bertina R.M., Koeleman B.P.C., Koster T., Rosendaal F.R., Dirven R.J., de Ronde H.D., van der Velden P.A., Reitsma P.H. Mutation in blood coagulation factor $\mathrm{V}$ associated with resistance to activated protein C. Nature 1994; 369: 64-67.

5. Jadaon M.M. Epidemiology of activated protein resistance and factor $\mathrm{V}$ Leiden mutation in the Mediterranean region. Mediterr J Hematol Infect Dis 2011; 3: e2011037.

6. Rees D.C., Cox M., Clegg J.B. World distribution of factor V Leiden. Lancet 1995; 346: 1133-1134.

7. Cox M.J., Rees D.C., Martinson J.J., Clegg J.B. Evidence of a single origin of factor V Leiden. Br J Haematol 1996; 92: 1022 1025 .
8. Zöller B., Hillarp A., Dahlbäck B. Activated protein C resistance caused by a common factor $\mathrm{V}$ mutation has a single origin. Thromb Res 1997; 85: 237-243.

9. Zivelin A., Griffin J.H., Xu X., Pabinger I., Samama M., Conard J., Brenner B., Eldor A., Seligsohn U. A single genetic origin for a common Caucasian risk factor for venous thrombosis. Blood 1997; 89: 397-402.

10. Jadaon M.M., Dashti A.A., Lewis H.L. What is the origin of factor V Leiden mutation in Arabs? The first molecular proof. J Thromb Haemost 2011; 9: P-MO-155. 